R.F.A Moritz

\title{
Nestmate recognition and the genetic relatedness of nests in the ant Formica pratensis
}

\begin{abstract}
Genetic relatedness of the mound-building ant Formica pratensis was determined by means of microsatellite DNA polymorphism, and its impact on nestmate recognition was tested in a population in Southern Sweden (Oeland). Recognition between nests was measured by testing aggression levels between single pairs of workers. The genetic distances of nests (Nei's genetic distance) and the spatial distance of nests were correlated and both showed a strong relation to the aggression behavior. Multiple regression analysis revealed a stronger impact of genetic relatedness rather than spatial distances on aggression behavior. Neighbouring nests were more closely related than distant nests, which may reflect budding as a possible spreading mechanism. The genetic distance data showed that nestmate recognition was strongly genetically influenced in $F$. pratensis.
\end{abstract}

Key words Nestmate recognition - Kin recognition · DNA fingerprinting $\cdot$ Aggression $\cdot$ Formica $\cdot$ Relatedness

M. Beye $(\varangle) \cdot$ P. Neumann · R.F.A Moritz

Institut für Ökologie und Biologie, Technische Universität Berlin, Franklinstrasse 28/29, D-10587 Berlin, Germany

e-mail: beye0736@mailszrz.zrz.tu-berlin.de,

Tel.: (49)(30)314 73318, Fax: (49)(30)314 73187

M. Chapuisat

Museum of Zoology, P.O. Box 448,

CH-1000 Lausanne 17, Switzerland

M. Chapuisat

Institute of Zoology and Animal Ecology,

CH-1015 Lausanne, Switzerland

P. Pamilo

Department of Genetics, Uppsala University,

Box 7003, S-75007 Uppsala, Sweden

\section{Introduction}

Social insects live in colonies and with few exceptions they resist mixing even within the same species. This is only possible if they are able to distinguish nestmates from non-nestmates. It has been argued that individuals recognize nest members through common labels or colony odors (Field 1903; Forel 1923). The recognition cues can be of genetic or environmental origin and different mechanisms have been found for a variety of different species (Wallis 1962; Mabelis 1979; Stuart 1987; Carlin and Hölldobler 1986; Waldman et al. 1988).

Nestmate recognition cues can be derived from environmental sources such as food and nesting material which are capable of overriding other more stable, apparently genetically based cues (Wilson 1971; Breed 1983; Gamboa et al. 1986a; Hölldobler and Wilson 1990). Carlin (1989) proposed that environmentally determined kin recognition cues in natural populations should serve as a null hypothesis in experimental work.

In spite of these environmental cues genetically determined discriminators have been suggested for various ant species (Mintzer 1982; Provost 1991; Waldman et al. 1988; Crozier and Dix 1979) and queens have been found to contribute substantially to the colony odour (Carlin and Hölldobler 1986, 1987). If nestmate recognition is truly genetically based then related nests should share more recognition cues and should therefore be less aggressive. Crozier and Pamilo (1996) pointed out that genetically based nestmate recognition is kin recognition at the colony level.

In this study we combine genetic data and information on aggressive behavior for a natural population of Formica pratensis and test the role of kinship on nestmate recognition. We assayed the aggression between nests on natural sites, and determined the relatedness of nests by means of microsatellite DNA polymorphisms. The standard genetic distance (Nei 1987) and the intranest relatedness of single nests, using a modification of the Queller and Goodnight algorithm (Queller and 
Goodnight 1989), was determined. In order to examine the impact of environmental cues on nestmate recognition the spatial distances between nests were used to test whether environmental cues change with distance.

\section{Methods}

The mound-building ant $F$. pratensis is typically found in xerothermic pastures and the populations tend to be patchy (Seifert 1996). Individual nests may often have several functional queens (Gösswald 1951; Seifert 1996) although monogyny can frequently occur (Rosengren et al. 1993; Pamilo 1987; Pamilo et al. 1994).

Ten $F$. pratensis nests were found on a pasture in the southern part of Oeland (Sweden) and behavioral assays were done in July (1992) in the field. No interconnecting trails were observed, so there was no indication of polydomy. The distances between nests ranged from $2.5 \mathrm{~m}$ to $260 \mathrm{~m}$.

\section{Behavioural analysis}

Aggression was tested between individual workers in arena tests (Beye et al. 1997). Two equally sized workers taken from the nest surface were confined in a neutral arena (petri dish which was quartered by cardboard barriers). Their behavioral interactions upon meeting were classified into three behavioral categories $(0=$ tolerance: huddling together, grooming, food exchange; 1 = avoid: jerking back at each encounter, 2 = fight: biting, spraying acid). The average scoring of the first ten interactions was used as a behavioral score in the further analysis. Fights exceeding $5 \mathrm{~s}$ were scored again at level 2 and counted as a new encounter, as well for the next $5 \mathrm{~s}$ and so on. Worker pairs from same nest served as controls. The dishes were cleaned after each encounter to remove potential contamination of the arena with formic acid or other alarm chemicals. Each pair of nests was tested with at least five replicates. Our ethological analyses were performed blind as we determined the genetic composition of nests after recognition analysis. We tested 24 possible combinations of nests to obtain aggression values for nests at different distances apart.

DNA isolation and microsatellite analysis

Up to 30 workers were taken from each nest and stored at $-20^{\circ} \mathrm{C}$. DNA from 5-15 individual workers was extracted in phenol following the protocol of Beye and Reader (1993) and resuspended in

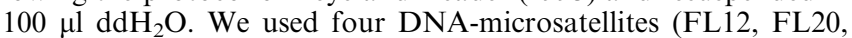
FL21 and FL29) from Formica lugubris B (renamed to F paralugubris) which were developed by Chapuisat (1996). Multiplex PCR was done using two pairs of loci (FL12-FL20, FL21-FL29) following the protocol of Chapuisat (1996). Amplification products were separated on polyacrylamide sequencing gels $(6 \%)$ for $4 \mathrm{~h}$ $(60 \mathrm{~W}) . \mathrm{M} 13 \mathrm{mp} 18$ control DNA sequencing reactions were run on the same gel as size standards. Microsatellite alleles were scored as fragment lengths in base pairs.

\section{Statistical analysis}

We calculated the standard genetic distance of Nei (1987):

$d=-\ln \frac{J_{12}}{\sqrt{J_{1}} \sqrt{J_{2}}}$ with $J_{1}=\sum p_{i}{ }^{2}, J_{2}=\sum q^{2}$, and $J_{12}=\sum p_{i} q_{i}$

where $J_{1}$ is the probability that two randomly chosen genes in nest A are identical, $J_{2}$ is the same for nest B, and $J_{12}$ is the probability that two genes, one drawn randomly from nest $\mathrm{A}$ and the other from nest B, are identical. This set was calculated for each locus. Finally the average for the four loci was calculated in each case.
The average intranest relatedness was determined using the jackknifed estimates of the Queller-Goodnight algorithm (Queller and Goodnight 1989). Queller and Goodnight (1989) suggested that their procedure for estimating average intranest relatedness could also be used for individual nests. However, Pamilo (1990) pointed out that these estimates can be prone to substantial biases in simple cases. We tried to overcome this bias by estimating the individual intranest relatedness $r i$ as follows:

$r i=\bar{r} n-\bar{r}_{(-i)}(n-1)$

$\bar{r}$ : jackknifed mean

$\bar{r}_{(-i)}$ : jackknifed value without colony $i$

ri: intracolonial relatedness of colony $i$

$n$ : number of colonies

Using this procedure it is possible to determine individual intranest relatedness $r i$ and a standard error (SE). We first estimated the average intranest relatedness, jackknifed the values and calculated the effect of each single nest on the average intranest relatedness. Finally, the mean intranest relatedness $r_{m}$ between pairs of nests was estimated. Nest 14 was excluded from this analysis because only five individuals could be genotyped. The statistical analyses were done using the SPSS statistic package.

For matrix correlations we used Mantel's test (Manly 1985), because the pairwise distance values between nests are not independent of each other. Our distance matrices have many missing values as the aggression tests were not carried out between all pairs of nests, and the matrix correlations are calculated from the existing distance values.

A linear model was used for multiple regression analysis in order to test the impact of different variables on aggression behavior. Both genetic distance and the spatial distance were logarithmically transformed (ln transformation) before using the linear model. We expected a ln adjustment would be necessary, since the level of aggression cannot exceed 2 in our assay. The ln transformation was used for spatial, genetic distance and mean intranest relatedness.

\section{Results}

Behavioural observations and genetic structure of nests

The occurrence and intensity of aggression was highly variable among nests. The 24 pairs of nests tested showed different levels of aggression ranging from mutual tolerance to fatal fights $(0.1-2$ on the aggression scale).

The four loci tested, FL12, FL20, FL 21 and FL29, revealed between 5 and 7 alleles per locus among the ten tested colonies with allele frequencies ranging from 0.01 to 0.75 (Table 1). The intranest relatedness $r_{i}$ ranged from 0 up to 0.54 with an average relatedness of $\bar{r}=0.14$ $\mathrm{SE} \pm 0.06$.

Aggression behavior, spatial distance, genetic distance and intranest relatedness

The aggression behavior between nests showed a correlation with the spatial distances of these nests (Fig. 1a, Mantel's test, Spearman's $\rho=0.61, P<0.05$; regression $P<0.001$ ). Ants from neighbouring nests behaved much less aggressively than ants from distant nests. However, the various nests were not part of a large 
polydomous nest, since ants from neighbouring nests interacted more aggressively than the controls, which never behaved aggressively. Moreover, there were no interconnecting trails between the nests. Finally, nearly all the nests had a specific genotypic composition $\left(\chi^{2}\right.$ test), although the differences between nests 2, 5 and 2, 6 were not significant.

Levels of aggression also increase with the standard genetic distance (Nei 1987) of nests (Fig. 1b, $P<0.001$, Mantel's test, Spearman's $\rho=0.65, P<0.05)$ suggesting that ants from unrelated pairs of nests tend to be more aggressive than related nests.

We also found a correlation between spatial nest distance and the genetic distance of nests (Fig. 1c, Mantel's test Spearman's $\rho=0.71, P<0.05$; regression $P<0.001$ ). Neighbouring nests tend to be more closely genetically related than distant nests. This seems plausible since spreading of ants often occurs by budding of nests, causing neighbouring nests to be genetically more similar.

To analyse whether the genetic diversity within individual nests influences nestmate recognition and aversion behavior, we determined intranest relatedness for each nest, modifying the Queller and Goodnight (1989) procedure as described in Eq. 2. The mean relatedness between pairs of nests was estimated $\left(r_{m}\right.$ : mean intranest relatedness), and they were compared with the worker pairs of aggression levels in the corresponding pairs. The correlation analysis reveals no significant influence of average intranest relatedness on the aggression behavior (Fig. 1d, $P>0.4$, Spearman's $\rho, P>0.3$ ). The intracolonial genetic diversity did not have any significant effect on the nestmate recognition system in $F$. pratensis. The slightly higher aggression in oligogynous nests $\left(r_{m}>0.25\right)$ was not significantly different from aggression levels in polygynous nests $\left(r_{m}<0.25\right)$.

Only the relatedness between nests (genetic distances) and the local habitat (as determined by spatial nest distances) correlated with the aggression behavior between nests. Both parameters were compared using a stepwise multiple regression of aggression between $F$. pratensis nests (dependent variable) on the spatial distance and genetic distance (Table 2). If the genetic distance of nests was entered first, the spatial distance had no significant effect. If we forced the spatial distance as the first variable entered, the genetic distances of nests still significantly improved the data fit $(P<0.05)$, indicating that the latter has a stronger impact on aggressive behavior than the first.

\section{Discussion}

Our results show that $F$. pratensis is able to recognize kin at the colony level, since the aggressive behavior of worker pairs decreased with increasing genetic relatedness. A positive correlation observed between the genetic distances and spatial distances suggests that environ- 

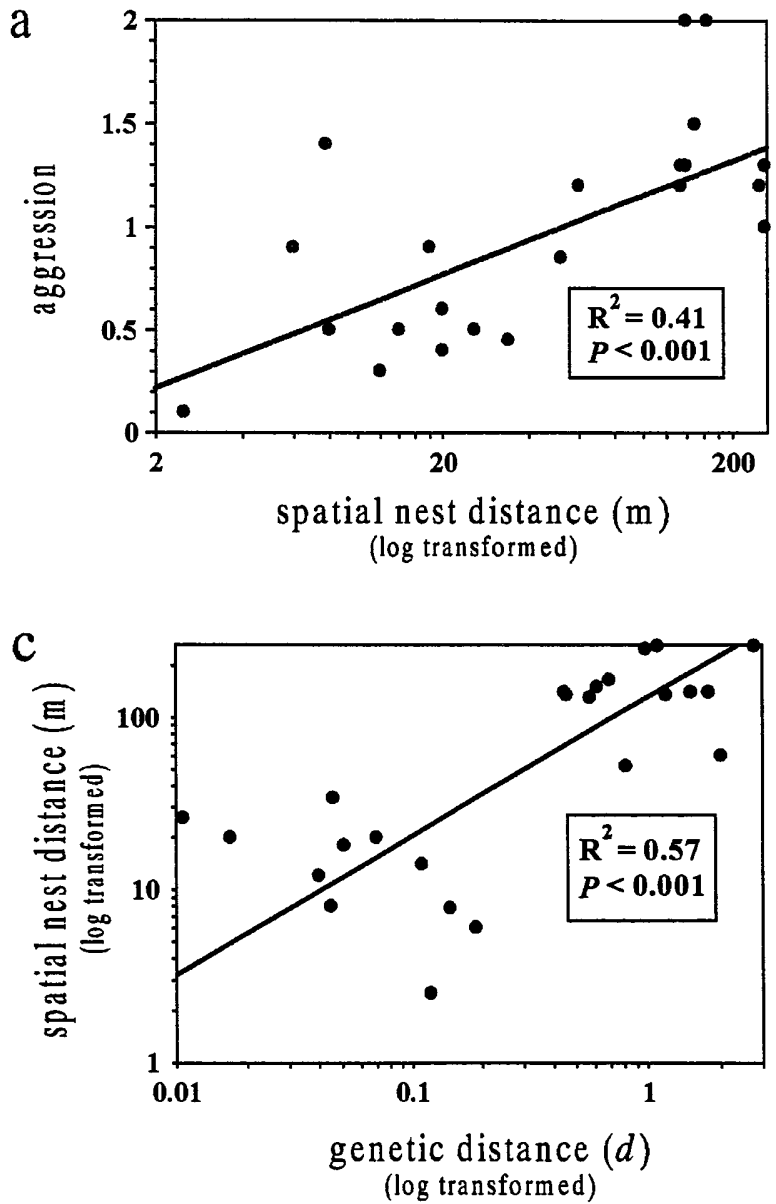

Fig. 1a-d Relation between aggression behavior, genetic distance (Nei 1987), spatial nest distance and the mean intranest relatedness. Each point represents the mean aggression score for one pair of nests. a Level of aggression responses between workers of different nests and distances of nests significantly correlate (Mantel's test, Spearman's $\rho=0.61, P<0.05)$. The best fit model of regression is a ln model $(P<$ 0.001 ), which fits the assumption well since aggression did not exceed 2 on the aggression scale. Neighbouring nests tend to be tolerant while distant nests tend to be more aggressive. $\mathbf{b}$ Level of aggressive responses between workers of different nests and the standard genetic distance (Nei 1987). Regression coefficient of the $\ln$ model significantly differ from 0 ( $P<0.001$; Mantel's test, Spearman's $\rho=0.65, P<0.05)$. This

Table 2 Summary table for the stepwise multiple regression of aggression behavior of Formica pratensis nests on the genetic distances and spatial distances. In the first run, none of the variables were forced, and they were entered by the program (SPSS) in the order of their unadjusted $R^{2}$ values until all of them were entered. The second step (spatial distance) did not significantly improve the

\begin{tabular}{|c|c|c|c|c|}
\hline Step & Variables & Total $R^{2}$ & Regression MS $(d f)$ & Residual MS $(d f)$ \\
\hline \multicolumn{5}{|c|}{ No variables forced } \\
\hline 1 & Genetic distance & 0.51 & $3.09(1)$ & $0.13(22)$ \\
\hline 2 & $\begin{array}{l}\text { Genetic and spatial } \\
\text { distance }\end{array}$ & 0.54 & $1.62(2)$ & $0.13(21)$ \\
\hline \multicolumn{5}{|c|}{ Spatial distance forced } \\
\hline 1 & Spatial distance & 0.41 & $2.49(1)$ & $0.16(22)$ \\
\hline $2 *$ & $\begin{array}{l}\text { Spatial and genetic } \\
\text { distance }\end{array}$ & 0.54 & $1.62(2)$ & $0.13(21)$ \\
\hline
\end{tabular}
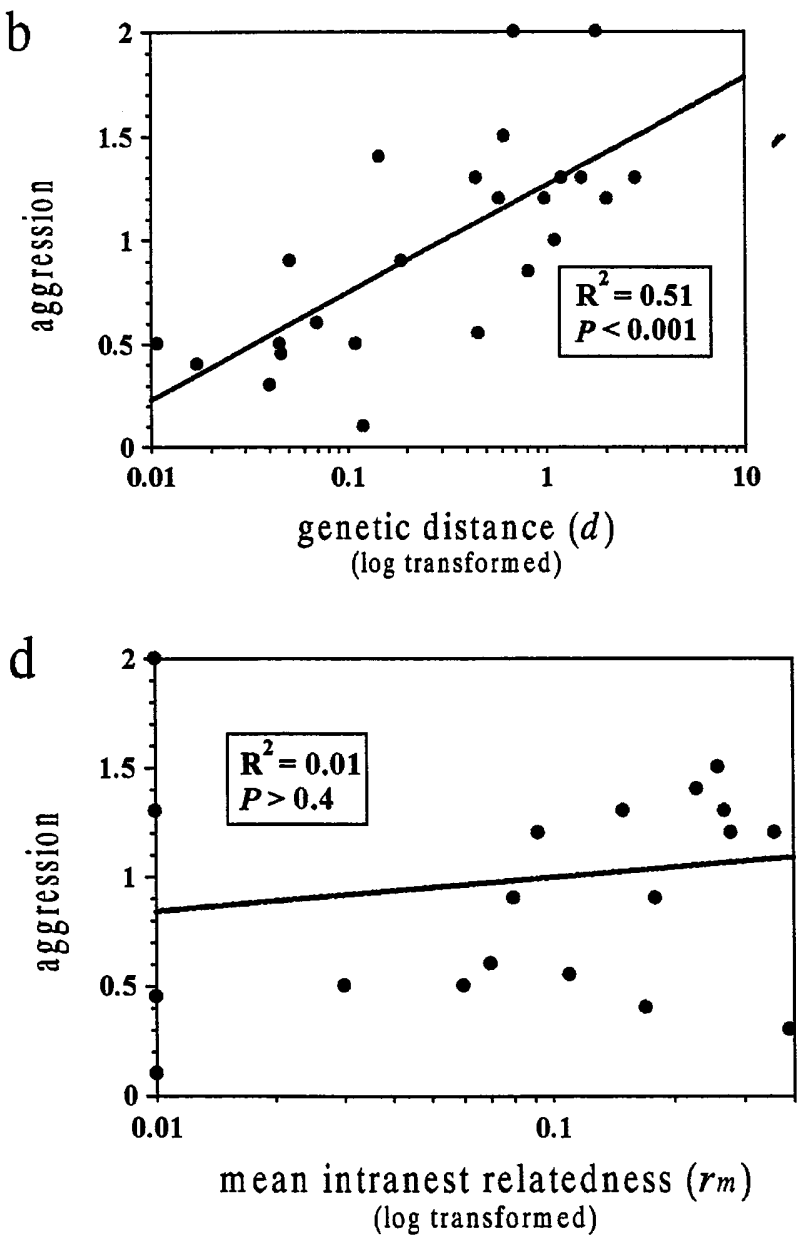

indicates effects of related genetic composition of nests on recognition and aversion behavior. c Spatial nest distances and genetic distance were correlated (Mantel's test, Spearman's $\rho=0.71, P<0.05$; regression $P<0.001)$ probably indicating the effect of budding behavior on the spatial population structure. d Aggression behavior and the mean intranest relatedness between nests did not show any correlation (Spearman's $\rho=P>0.3$; regression $P>0.4$ ). The mean genetic diversity of pairs of nests has no major influence on recognition and aversion behavior. Please notice that the mean intranest relatedness result is based on fewer (20) estimates than the genetic distances and spatial distances (both 24 estimates) since the intranest relatedness of nest 14 was not determined

data fit. In the second run the spatial distance was forced as the first variable entered. Adding the genetic distance to the model significantly improved the data fit, indicating a significant influence of genetic relatedness on nestmate recognition and aversion behaviour.

\footnotetext{
* Significant improvement of the data fit $P<0.05$
} 
mental cues associated to spatial proximity might lead to similar results. However, multiple regression indicates that the genetic similarity more strongly affects aggressive behavior than spatial proximity. Consequently, the null hypothesis of all kin recognition that environmental cues alone determine the recognition mechanism (Carlin 1989) can be rejected for the $F$. pratensis population studied here. Nestmate recognition in $F$. pratensis thus has a strong genetic component, although we cannot exclude that environmental cues additionally contribute to the recognition system.

Polygynous nests should have a higher variance of potential genetic based recognition cues as compared to oligogynous nests. Higher diversity of recognition cues found in one nest, which was estimated by means of intranest relatedness, can have two consequences in recognition mechanisms:

1. It can enhance nestmate recognition because the specific genotypic composition of a colony results in a "unique" recognition cue combination. If workers can discriminate these complex cues, discrimination between nestmates and foreign workers should be more precise.

2. Higher diversity of intracolonial recognition cues can decrease the ability for nestmate recognition, if workers do not use the typical colony gestalt label, but individual recognition labels instead. A large variety of intranest labels would render it difficult to discriminate them from similar labels of foreign nests.

Since we fail to detect any effect of average intranest relatedness on aggressive behavior, we find no support for either theory.

There are many studies that try to distinguish between genetic and environmental factors in nestmate recognition (reviewed by Waldman et al. 1988). Several examples of genetically determined cues have been presented (for overview see Waldman et al. 1988; Crozier and Pamilo 1996) and transfer experiments exceeding the age of a single worker cohorts showed that recognition in the ant $F$. uralensis depended on genealogical history rather that spatial distance (Rosengren and $\mathrm{Pa}-$ milo 1983). Beye et al. (1997) also showed a strong effect of genetic components in the ant $F$. polyctena using a genetic gestalt distance of nests. In both $F$. polyctena and $F$. pratensis, internest spatial distance played a minor or no role in nestmate recognition

Effects of environmental cues such as food or nesting material are hard to quantify; nevertheless, other authors have found a strong relation of aggression behavior and habitat at different spatial distances of nests in Leptothorax (Stuart 1987; Heinze et al. 1996). For example, Heinze et al. (1996) were able to show that different nesting material has a major influence on nestmate recognition in L. nylanderi, indicating a strong environmental effect. A failure to detect significant environmental components in $F$. pratensis could partly reflect the homogeneity of local environmental conditions (and therefore homogeneity of potential signals). Formica ants in pine forests ( $F$. polyctena) and pasture
(F. pratensis) may utilize similar nesting materials or food sources which renders it impossible to acquire distinct environmental labels. This contrasts with the study of Heinze et al. (1996) on L. nylanderi nesting in very different types of woods (oak/pine). It should, however, be noted that although Rosengren and Pamilo (1983) moved $F$. uralensis ants to a completely different area (at a distance of $50 \mathrm{~km}$ ), the genetic relationships overruled the environmental differences in recognition tests.

Various authors have suggested that nestmate recognition in social insects may generally have both genetic and environmental components (Wilson 1971; Jutsum et al. 1979; Breed 1983). It seems however clear, that the relative contributions of genes and environment can vary dramatically depending on the species under study. The ability to maintain colony autonomy even in homogenous habitats is extremely important. In such cases genetically based recognition cues are the prime mechanism to permit the segregation of colonies (Gamboa et al. 1986b). Environmental cues may play a more prominent role in nestmate recognition if habitats are heterogeneous and cues of different nesting materials or food sources can serve as labels.

Acknowledgements We are very grateful to the students of the field trip to Oeland in 1992 for recognition analysis. We also thank F. El Bouamraoui for the microsatellite analysis and thank two anonymous reviewers for helpful comments on the paper. This study was supported by the DFG, the DAAD and the Research Council of Natural Sciences of Sweden.

\section{References}

Beye M, Raeder U (1993) Rapid DNA preparation from bees and $\%$ GC fractionation. BioTechniques 14:372-374

Beye M, Neumann P, Moritz RFA (1997) Nestmate recognition and the genetic gestalt in the mound-building ant Formica polyctena. Insectes Soc 44:49-58

Breed M (1983) Nestmate recognition in honey bees. Anim Behav 31:86-91

Carlin NF (1989) Discrimination between and within colonies of social insects: two null hypotheses. Neth J Zool 39:86-100

Carlin NF, Hölldobler B (1986) The kin recognition system of carpenter ants (Camponotus spp.). I. Hierarchical cues in small colonies. Behav Ecol Sociobiol 19:123-134

Carlin NF, Hölldobler B (1987) The kin recognition system of carpenter ants (Camponotus spp.). II Larger colonies. Behav Ecol Sociobiol 20:209-217

Chapuisat M (1996) Characterization of microsatellite loci in Formica lugubris $B$ and their variability in other ant species. Mol Ecol 5:124-1

Crozier RH, Dix M (1979) Analysis of two genetic models for innate components of colony odor in social Hymenoptera. Behav Ecol Sociobiol 4:217-224

Crozier RH, Pamilo P (1996) Evolution of social insect colonies. Oxford University Press, Oxford

Field AM (1903) Artifical mixed nests of ants. Biol Bull 5:320-325

Forel A (1923) Le monde social des fourmis, vol 4 Kundig, Geneva

Gamboa GJ, Reeve HK, Ferguson D, Wacker TL (1986a) Nestmate recognition in social wasps: the origin and acquisition of recognition odours. Anim Behav 34:685-695 
Gamboa GJ, Reeve HK, Pfennig DW (1986b) The evolution and ontogeny of nestmate recognition in social wasps. Annu Rev Entomol 31:431-454

Gösswald K (1951) Über den Lebenslauf von Kolonien der roten Waldameise. Zool Jb Abt Syst 80:27-63

Heinze J, Foitzik S, Hippert A, Hölldobler B (1996) Apparent dearenemy phenomenon and environment-based recognition cues in the ant Leptothorax nylanderi. Ethology 102:510-522

Hölldobler B, Wilson EO (1990) The ants. Harvard University Press, Cambridge

Jutsum AR, Saunders TS, Cherrett JM (1979) Intraspecific aggression in the leaf-cutting ant Acromyrmex octospinosus. Anim Behav 27:839-844

Mabelis AA (1979) Wood ant wars: the relationship between aggression and predation in the red wood ant (Formica polyctena Forster). Neth J Zool 29:109-120

Manly BFJ (1985) The statistics of natural selection. Chapman and Hall, London

Mintzer A (1982) Nestmate recognition and incompatibility between colonies of the acacia ant Pseudomyrmex ferruginea. Behav Ecol Sociobiol 10:165-168

Nei M (1987) Molecular evolutionary genetics. Columbia University Press, New York

Pamilo P (1987) Population genetics of the Formica group. In: Eder J, Remboldt H (eds) Chemistry and biology of social insects. Peperny, München, pp 68-70

Pamilo P (1990) Comparison of relatedness estimator. Evolution 44:1378-1382
Pamilo P, Sundström L, Fortelius W, Rosengren R (1994) Diploid males and colony level selection in Formica ants. Ethol Ecol Evol 6:221-235

Provost E (1991) Nonnestmate recognition in the ant Leptothorax lichtensteini: evidence that genetic factors regulate colony recognition. Behav Genet 21:151-167

Queller DC, Goodnight KF (1989) Estimating relatedness using genetic markers. Evolution 43: 258-275

Rosengren R, Pamilo P (1983) The evolution of polygyny and polydomy in mound building Formica ants. Acta Entomol Fenn 42:65-77

Rosengren R, Sundström L, Fortelius W (1993) Monogyny and polygyny in Formica ants: the results of alternative dispersal tactics. In: Keller L (ed) Queen number and sociality in insects. Oxford University Press, Oxford, pp 308-333

Seifert B (1996) Ameisen: beobachten, bestimmen. Naturbuch, Augsburg

Stuart RJ (1987) Transient nestmate recognition cues contribute to a multicolonial population structure in the ant, Leptothorax curvispinosus. Behav Ecol Sociobiol 21:229-235

Waldman B, Frumhoff PC, Sherman PW (1988) Problems of kin recognition. Trends Ecol Evol 3:8-13

Wallis DI (1962) Aggressive behaviour in the ant Formica fusca. Anim Behav 10:267-274

Wilson EO (1971) The insect societies. Belknap Press of Harvard University Press, Cambridge

Communicated by R.H. Crozier 